\section{Assessment of the appropriate- ness of antibiotic prescriptions in Lesotho public hospitals: a novel methodology based on principles of antibiotic prescribing}

\author{
Matthias Adorka, ${ }^{1}$ \\ Honoré Kabwebwe Mitonga, ${ }^{2}$ \\ Martie Lubbe, ${ }^{3}$ Jan Serfontein, ${ }^{3}$ \\ Kirk Allen ${ }^{4}$ \\ 1School of Pharmacy, University \\ of Namibia, Windhoek, Namibia; \\ 2Department of Community Medicine, \\ University of Namibia, Windhoek, \\ Namibia; ${ }^{3}$ Medicine Usage in South \\ Africa, School of Pharmacy, North-West \\ University, Potchefstroom, South Africa; \\ 4 Medical and Pharmaceutical \\ Biotechnology Unit, Research Center in \\ Technology and Design Assistance of \\ Jalisco State (CIATEJ), Guadalajara, \\ Mexico
}

\section{Abstract}

The study primarily aimed at assessing the appropriateness of antibiotic prescriptions in a section of public health institutions in Lesotho using an assessment tool formulated from principles of antibiotic prescribing. Relevant data on procedures of infection diagnosis and prescribed antibiotics were collected from both inpatient and outpatient case reports for a onemonth period in five public hospitals in Lesotho. These were analyzed for the appropriateness of the prescribed antibiotics. Prescription appropriateness assessment was based on conformities of prescribed antibiotics to criteria developed from pertinent principles of antibiotic prescribing. Assessed prescriptions, 307 inpatient and 865 outpatient prescriptions in total, were classified into categories of appropriateness based on extents to which they satisfied conditions defined by combinations of criteria in the assessment tool. Antibiotic prescriptions from inpatient and outpatient departments of study site hospitals were categorized into groups of different degrees of appropriateness. A total of $32.2 \%$ inpatient prescriptions and $78.4 \%$ outpatient prescriptions assessed were appropriately written for the empiric treatment of infections for which bacterial pathogens were considered absolute or possible etiologies. The use of prescription assessment tools based on principles of antibiotic prescribing is a feasible option of assessing the appropriateness of antibiotic prescriptions, particularly in low-income countries where expert panels cannot be formed.

\section{Introduction}

The World Health Organization, in its document on global strategy for containment of antimicrobial resistance, noted inappropriate prescribing and use of antibiotics as factors that both compromise treatment outcomes and contribute to the development of pathogen resistance to antibacterial agents. ${ }^{1}$ It further stressed the need for research towards filling gaps in existing knowledge in antibiotic prescribing.

Although prescribers are often assumed to be prescribing antibiotics appropriately, making clinical decisions to initiate antibiotic therapy and selecting antibiotics appropriately in cases of established infections can be challenging. In principle, this calls for the prescriber to establish the presence of an infection to justify his or her decision to prescribe an antibiotic. In the cases of persons in longterm-care facilities, for example, it can be difficult to establish a diagnosis of infection in some patients. ${ }^{2}$ In other cases, diagnosis of bacterial infections may be difficult because of the resemblance of clinical symptoms classically identified with certain bacterial infections with symptoms of other types of infections or disease conditions that do not have pathogenic bacteria as etiologies. Classic examples are the similarities of symptoms of viral and bacterial infections of the respiratory tract. $^{3}$ Descriptively, symptoms of protozoal infections of the vagina manifesting as discharges similarly bear resemblance with symptoms of bacterial infections caused by Neisseria gonorrhea or Chlamydia trachomatis. ${ }^{4}$ Even in cases where bacteria pathogens may be etiologies of a diagnosed infection, an antibiotic prescribed for such an infection may be considered appropriate only when it targets, in terms of its activity, the exact pathogen or pathogens causing that infection. ${ }^{5}$ In this respect, and for it to be judged appropriately prescribed, factors that determine the therapeutic efficacy of the antibiotic would have to be considered also. For example, these include the antibiotic's spectrum of activity, its physicochemical, pharmacokinetic and pharmacodynamic properties and its compatibility with other antibiotics in situations of multiple antibiotic prescribing. ${ }^{6,7}$ Taking these into account, prescribing antibiotics appropriately can be expected to be a challenging duty and designing procedures for assessing the appropriateness of antibiotic prescriptions a difficult and complicated task.

Many studies that investigate appropriateness of antibiotic prescriptions audit antibiotic prescribing by determining extents to which antibiotics are prescribed in conformity to treatment guidelines or some criteria of appro-
Correspondence: Matthias Adorka, School of Pharmacy, University of Namibia, Windhoek, Namibia.

Tel. +264.612065026 (office) / +264.817761424 (mobile) - Fax: +264.612065091

E-mail: madorka@yahoo.com

Key words: antibiotic prescriptions, appropriateness, alternative method, bacterial etiologies, Lesotho.

Acknowledgements: we acknowledge the role of our field workers, namely Lerata M.S., Lebeko T. M. and Ralimpe T.C. all of the Department of Pharmacy of the Faculty of Health Sciences of the National University of Lesotho in the collection and summarization of prescription data for this study. We also thank the National University of Lesotho for its partial funding of the cost of this study.

Funding: this project and the preparations of al reports thereof were funded partly from resources of the first author and a research grant from the National University of Lesotho.

Conflict of interests: the authors declare no potential conflict of interests.

Received for publication: 28 June 2013.

Revision received: 19 November 2013.

Accepted for publication: 4 February 2014.

This work is licensed under a Creative Commons Attribution NonCommercial 3.0 License (CC BYNC 3.0).

(C) Copyright M. Adorka et al., 2014

Licensee PAGEPress, Italy

Journal of Public Health in Africa 2014; 5:354 doi:10.4081/jphia.2014.354

priateness based on opinions of antibiotic experts. In clinical environments where neither elaborate antibiotic treatment guidelines nor services of antibiotic experts are available, it may become necessary to assess the appropriateness of antibiotic prescriptions using alternative but equally versatile procedures. This article presents a methodology of assessing antibiotic prescriptions using a computer assisted procedure in determining the appropriateness of these prescriptions based on their conformities to sets of criteria formulated from basic principles of antibiotic prescribing. It also provides details of the methodology we used to develop an antibiotic prescription classification system as reported in our earlier published work on the impact of appropriate antibiotic prescribing on treatment evaluation parameters. ${ }^{8}$ Our methodology also demonstrated an added advantage of providing data that could be analyzed to make information available on sources of inappropriate prescribing in respect to specified criteria. We consider such information useful in formulating 
antibiotic prescribing policies aimed at promoting appropriate prescribing.

\section{Materials and Methods}

\section{Objectives}

The primary objective of this article is to present details of procedures used to develop an antibiotic prescription classification system that avoids dependence on expert opinions or treatment guidelines in determining appropriateness of antibiotic prescriptions.

\section{Methodology}

Relevant data on procedures of infection diagnosis and prescribed antibiotics were collected from patients' case notes within a onemonth period in five public hospitals in Lesotho. The prescriptions were assessed for their appropriateness on the basis of their conformities to sets of criteria developed from principles of antibiotic prescribing as detailed below. In all, 307 inpatient and 865 outpatient prescription records were assessed. Ethical permissions in accordance with the Helsinki Declaration were received from both the Ministry of Health of Lesotho through its ethics committee for public hospitals and individual Christian Health Association of Lesotho (CHAL) hospitals, as well as the ethics committee of the North-West University (South Africa).

Statements on guiding principles of antibiotic prescribing were developed into criteria (Table 1) and formulated into a prescription assessment tool. Responses of Yes, No or Not applicable to questions in the assessment tool were assessed. A table indicating the diagnoses, symptoms and etiologies of infections as reviewed from the literature was compiled. This was used as a reference source in the data compilation procedures to make decisions on whether or not diagnosed infections for which antibiotics were prescribed were of bacterial causes.

Using Statistical Analysis Systems ${ }^{\circledR}$ (SAS) for Windows $9.1^{\circledR}$, prescriptions' conformities to developed criteria were combined into conditions. The conditions defined both the extent to which the presence of infections were established prior to antibiotic prescribing and the extent to which antibiotics were prescribed appropriately (Tables 2 and 3). The conditions were combined further into seven categories of prescription appropriateness (Tables 4 and 5 ). The use of the procedures enabled the categorization of all prescriptions studied into the different categories of appropriateness.

\section{Results}

All 307 inpatient and 865 outpatient antibiotic prescriptions were categorized into the seven predefined categories of prescription appropriateness. A total of $28.2 \%$ of inpatient and $78.4 \%$ of outpatient prescriptions were written appropriately for the treatment of infections (categories A1 and A2). This is in comparison with $47.9 \%$ of inpatient and $18.7 \%$ of outpatient prescriptions that were prescribed inappropriately for the treatment of infections or prescribed inappropriately for diagnosed clinical conditions for which use of antibiotics were considered not justified (categories B and F) (Table 6).

\section{Discussion}

\section{Methodologies of assessing appropriateness of antibiotic prescriptions}

In studies on the assessment of appropriateness of antibiotic prescriptions, instruments were based most commonly on judgments of panels of antibiotic experts, ${ }^{9-12}$ or on prescribing recommendations in infection treatment guidelines. ${ }^{13-15}$ Assessment procedures based on judgments of experts were mostly based on direct judgments on the appropriateness of prescriptions at panel sittings where prescrip- tions were examined. ${ }^{9,10}$ In some cases such judgments were based on prescription conformities to criteria previously developed by an expert or panel of experts which in themselves may be based on provisions of recommendations in national guidelines. ${ }^{11,12}$

Though undeniably a popular method of assessing antibiotic prescriptions, the use of panels of experts in assessing antibiotic prescriptions is not without shortcomings. Typically, difficulties may be encountered in obtaining agreements and consistencies in scorings of such panels. ${ }^{10}$ Engaging the services of antibiotic experts may also increase research costs and limit the use of the methodology in resource-limited countries. It may also be inapplicable in clinical environments where these experts are not available. Under these circumstances, an alternative procedure could be to base prescription assessment on the use of instruments developed from recommendations in antibiotic treatment guidelines. In clinical environments where elaborate antibiotic treatment guidelines are not available, the development of such instruments may be limited. These situations exist in Lesotho, and may also be prevailing in a number of resource-limited countries. They make alternative methods of assessing the appropriateness of antibiotic prescriptions worthwhile.

The methodology of assessing the appropriateness of antibiotic prescriptions in this study employed an instrument developed from principles of antibiotic prescribing as documented in literature. These included essentially the

Table 1. Criteria for determining appropriateness of antibiotic prescriptions.

\begin{tabular}{ll} 
Criterion no. & \multicolumn{1}{c}{ Criterion definition } \\
\hline 2 & Suggestive signs and symptoms of infection present \\
\hline 4 & $\begin{array}{l}\text { Presenting signs and symptoms absolute for bacterial infection } \\
\text { Site of infection or possible site for infection identified }\end{array}$ \\
\hline 5 & $\begin{array}{l}\text { Potenti al source of infection } \text { e.g. indwelling catheters and prosthetic devices or surgical } \\
\text { and other open wounds present }\end{array}$ \\
\hline 6 & Presence of infection established by or objective data \\
\hline 9 & Presence of infection inferred from symptoms only \\
\hline 10 & Antibiotic prescribed alone \\
\hline 11 & Initial antibiotic treatment modified by addition of other antibiotics \\
\hline 12 & Initial antibiotic treatment modified by substitution of other antibiotics \\
\hline 13 & Antibiotics in multiple therapy compatible \\
\hline 14 & $\begin{array}{l}\text { Spectra of activity of } 2 \text { or more antibiotics in multiple antibiotic therapy similar } \\
\text { of infection }\end{array}$ \\
\hline 15 & Bacterial morphological and grams stain performed before therapy initiation \\
\hline 16 & Culture sensitivity test performed before initiation of or during antibiotic therapy \\
17 & Culture sensitivity test requested before antibiotic therapy initiation \\
\hline 18 & Culture sensitivity test performed in the course of antibiotic therapy \\
\hline & Antibiotic choice based on culture sensitivity test results \\
\hline
\end{tabular}


principles of: i) establishing presence and sites of infections prior to antibiotic prescribing:7,16,17 ii) establishing potential sources of infection or comorbid conditions predisposing patients to certain infections prior to prescribing antibiotics for prophylactic reasons, ${ }^{7,18,19}$ iii) making appropriate antibiotic selections for empiric or definitive treatment of infections including establishing the need for and ensuring the effectiveness of prescribed antibiotics; $;, 7,16,17,20,21$ and iv) appropriately selecting and initiating antibiotic therapy in clinically ill or hospitalized patients. ${ }^{16,17,22}$ The method generally assessed antibiotic prescriptions against the establishment of the need for antibiotic use in circumstances for which the drugs were prescribed. It also assessed the appropriate prescribing of the agents with respect to their doses, compatibility with coprescribed antibiotics as well as their effectiveness in treating infections for which they have been prescribed. By avoiding the use of either the services of antibiotic experts or criteria compiled solely from elaborate antibiotic treatment guidelines, our method provides a novel approach to assessing antibiotic prescriptions in clinical environments that lack these amenities.

\section{Prescription assessment results}

Antibiotic prescribing in outpatient settings appeared to be more appropriate than in inpatient settings. However, 55.8\% (378 of 677) were cases for which the agents were prescribed for infections with suspected bacterial etiologies (category A2). To be adjudged appropriately prescribed, antibiotics need to be both prescribed first and foremost for infections with bacterial etiologies and also selected to provide antimicrobial coverage for the diagnosed infection.1,23 Categorizing antibiotic prescriptions written for suspected bacterial infections points to a problem area of antibiotic prescribing that needs redress. We consider this an advantage of the methodology. Based on the types of infections encountered most at the setting, prescribers could establish the presence of infections from sites and symp- toms of infections to justify their decisions to prescribe antibiotics. For such infections, they may lack the means or the expertise to differentially diagnose these infections and confirm bacterial pathogens as their etiologies before prescribing antibiotics. The prescription of antibiotics for infections of upper respiratory tract infections (URTIs) is a standard case of reference in such instances. These infections as seen in outpatient settings have been shown to be mainly of viral etiologies with less than $2 \%$ being of bacterial causes. ${ }^{24}$ In the absence of differential diagnosis, a majority of antibiotic prescriptions classified as category A2 may actually be given for the treatment of URTIs or other types of infections which may not have bacterial causes.

A total of $30.0 \%$ of inpatient prescriptions were inappropriately prescribed for the empiric treatment of infections (Category B) and $17.9 \%$ were prescribed for clinical conditions for which use of antibacterial agents were deemed not justified (Category F). The results highlight inabilities of prescribers to select appropriate antibiotic treatments for diag-

Table 2. Criteria combinations and their indications: inpatient prescription assessment.

\begin{tabular}{|c|c|c|}
\hline Condition ${ }^{\#}$ & Criteria grouping & Indication \\
\hline I & Yes for criteria 1,2 and 3 or 5 & Presence of infection or need for antibiotic use for treatment established \\
\hline II & Yes for criteria 1,3 and 6 and $N o$ for 2 and 5 & Bacterial Infection may be present though not confirmed \\
\hline III & Yes for criteria 3 and 4 and $N o$ for criterion 1 & Need for antibiotic use for prophylaxis established \\
\hline IV & No for $1,2,3$, and 5 OR No for 1,2 , and 5 and "NA" for 3 & $\begin{array}{l}\text { Presence of infection or need for antibiotic use for treatment NOT } \\
\text { established }\end{array}$ \\
\hline V & $\begin{array}{l}\text { No for } 1,2,3 \text { and } 4 \text { OR No for } 1,2 \text {, and } 4 \text { OR No } \\
\text { for 1,2,3 and } 4 \text { OR No for 1,2, and } 4 \text { "NA" for } 3\end{array}$ & Need for antibiotic use for prophylaxis NOT established \\
\hline VI & $\begin{array}{l}\text { Yes for } 7 \text {, and } 13 \text { and No for } 8 \text { and } 17 \text { OR } \\
\text { Yes for } 7 \text {, and } 14 \text { and No for } 8 \text { and } 17\end{array}$ & Principles of empiric prescribing of single antibiotic for treatment followed \\
\hline VII & $\begin{array}{l}\text { No for } 7 \text { and } 12 \text { and No for } 8 \text { and } 17 \text { and Yes } \\
\text { for } 11 \text { and } 13 \text { OR No for } 7 \text { and } 12 \text { and No for } 8 \text { and } 17 \text { and } \\
\text { Yes for } 11 \text { and } 14 \text { OR No for } 7 \text { and } 12 \text { and No for } 9 \text { and } 17 \\
\text { and Yes for } 11 \text { and } 13 \text { OR No for } 7 \text { and } 12 \text { and } N o \text { for } 9 \\
\text { and } 17 \text { and Yes for } 11 \text { and } 14\end{array}$ & Principles of empiric prescribing of multiple antibiotics for treatment followed \\
\hline VIII & Yes for 7 and $N o$ for 13 & Principles of empiric prescribing of single antibiotic for treatment NOT followed \\
\hline IX & No for 7 and 10 OR No for 6 and Yes for 11 OR No for 7 and 13 & Principles of empiric prescribing of multiple antibiotics for treatment NOT followed \\
\hline$X$ & Yes for 17 and $N o$ for 18 & Principles of empiric prescribing of antibiotic(s) for treatment NOT followed \\
\hline XI & $\begin{array}{l}\text { Yes for } 8 \text { and } 17 \text { No for } 16 \text {, and } 18 \text { OR } \\
\text { Yes for } 9 \text { and } N o \text { for } 16 \text {, and } 18\end{array}$ & Principles of empiric prescribing of antibiotic(s) for treatment NOT followed \\
\hline XII & No for 10 & Medication error in antibiotic prescribing \\
\hline XIII & $\begin{array}{l}\text { Yes for } 7,16 \text {, and } 18 \text { and } N o \text { for } 8 \mathrm{OR} \\
\text { Yes for } 7,16 \text {, and } 18 \text { and } N o \text { for } 8 \\
\text { Yes for } 7,16 \text {, and } 18 \text { and } 9\end{array}$ & Principles of antibiotic prescribing based on CST results followed \\
\hline XIV & $\begin{array}{l}\text { No for } 7 \text { and } 8 \text { and Yes for } 11,16 \text {, and } 18 \mathrm{OR} \\
\text { No for } 7 \text { and } 8 \text { and Yes for } 11,16 \text {, and } 18 \mathrm{OR} \\
\text { No for } 7 \text { and Yes for } 9,11,16 \text { and } 18\end{array}$ & Principles of antibiotic prescribing based on CST results followed \\
\hline XV & Yes for 3 and 4 and 7 , and 13 & Principles of antibiotic prescribing in prophylaxis followed \\
\hline XVI & Yes for $3,4,11$, and 13 and $N o$ for 7 and 12 & Principles of antibiotic prescribing in prophylaxis followed \\
\hline XVII & Yes for 3 and 4 and 7 and $N o$ for 13 & Principles of antibiotic prescribing in prophylaxis NOT followed \\
\hline XVIII & $\begin{array}{l}\text { Yes for } 3 \text { and } 4 \text { and } N o \text { for } 7 \text { and } 11 \text { OR } \\
\text { Yes for } 3,4 \text { and } 12 \text { and } N o \text { for } 7 \text { OR } \\
\text { Yes" for } 3 \text {, and } 4 \text { and } N o \text { for } 7 \text { and } 13\end{array}$ & Principles of antibiotic prescribing in prophylaxis NOT followed \\
\hline
\end{tabular}

NA, not applicable; CST, culture sensitivity test. 
nosed infections as the more prominent of the causes of inappropriate prescribing of antibiotics in inpatient settings of study site hospitals. The reverse was true for outpatient departments where most inappropriately prescribed antibiotics were indicated for clinical conditions not requiring antibiotic treatments.

Antibiotic prescribing for infection prophylaxis was done mostly in inpatient settings. This was expected because such modes of antibiotic usage are encountered more in sur- gical wards where the agents are commonly prescribed for preventing post-surgical wound infections than in medical wards where the agents are most used for treating rather than preventing infections. An almost equal percentage of prescriptions were written appropriately (category D) and inappropriately (category E) for purposes of preventing infections in inpatient settings. This result may be a problem of inappropriate prescribing of the antibiotics for prophylactic reasons in the inpatient setting. The $1.3 \%$ of inpatient prescriptions with antibiotics prescribed according to results of culture sensitivity tests and with none such prescriptions identified from outpatient departments, documents essentially empiric prescribing of antibiotics as a mainstay of treating infections at study site hospitals. This is a significant finding as it accentuates the importance of prescribers' appropriate selection and prescribing of the agents to ensure the effective treatment of infections.

Table 3. Criteria combinations and their indications: outpatient prescription assessment.

\begin{tabular}{|c|c|c|}
\hline Condition\# & Criteria grouping & Indication \\
\hline I & Yes for criteria 1,2 and 3 OR Yes for 5 & Presence of infection or need for antibiotic use for treatment established \\
\hline II & $\begin{array}{l}\text { Yes for } 1,3 \text {, and } 6 \text { and } N o \text { for } 2 \text { and } 5 \text { OR } \\
\text { Yes for } 1 \text {, and } 6 \text { and } N o \text { for } 2,3 \text { and } 5\end{array}$ & Bacterial Infection may be present though not confirmed \\
\hline III & Yes for criteria 3 and 4 and $N o$ for 1 & Need for antibiotic use for prophylaxis established \\
\hline IV & No for $1,2,3$ and 5 Or $N o$ for 1,2 , and 5 and "NA" for 3 & Presence of infection or need for antibiotic use for treatment NOT established \\
\hline $\mathrm{V}$ & No for 1,2 , and 4 and "NA" for 3 OR $N o$ for $1,2,3$ and 4 & Need for prophylactic use of antibiotic NOT established \\
\hline VI & "Yes for 7 and 13 OR Yes for 7 and 14 & Principles of empiric prescribing of single antibiotic for treatment followed \\
\hline VII & $\begin{array}{l}\text { No for } 7 \text { and } 12 \text { and Yes for } 11 \text { and } 13 \text { OR } \\
\text { No for } 7 \text { and } 12 \text { and Yes for } 11 \text { and } 14\end{array}$ & Principles of empiric prescribing of multiple antibiotics for treatment followed \\
\hline VIII & Yes for 7 and No for 13 & Principles of empiric prescribing of single antibiotic for treatment NOT followed \\
\hline IX & $\begin{array}{l}\text { No for } 7 \text { and } 11 \text { OR No for } 7 \text { and Yes for } 12 \text { OR No } \\
\text { for } 7 \text { and } 13\end{array}$ & $\begin{array}{l}\text { Principles of empiric prescribing of multiple antibiotics for treatment } \\
\text { NOT followed }\end{array}$ \\
\hline$X$ & Yes for 15 and No for 18 & Principles of empiric prescribing of antibiotic(s) for treatment NOT followed \\
\hline $\mathrm{XI}$ & No for 10 & Medication error in antibiotic prescribing \\
\hline XII & Yes for 7,15 , and 18 & Principles of antibiotic prescribing based on CST results followed \\
\hline XIII & No for 7 and Yes for 11,15 , and 18 & Principles of antibiotic prescribing based on CST results followed \\
\hline XIV & Yes for $3,4,7$, and 13 & Principles of antibiotic prescribing in prophylaxis followed \\
\hline $\mathrm{XV}$ & Yes for $3,4,11,13$ and $N o$ for 7 and 12 & Principles of antibiotic prescribing in prophylaxis followed \\
\hline XVI & Yes for 3,4 and 7 and $N o$ for 13 & Principles of antibiotic prescribing in prophylaxis NOT followed \\
\hline XVII & $\begin{array}{l}\text { Yes for } 3,4 \text { and } 12 \text { and } N o \text { for } 7 \text { and } 11 \text { OR Yes } \\
\text { for } 3,4 \text { and } 12 \text { and } N o \text { for } 7 \text { and } 13\end{array}$ & Principles of antibiotic prescribing in prophylaxis NOT followed \\
\hline
\end{tabular}

Table 4. Inpatient prescription appropriateness categorization.

\begin{tabular}{|c|c|c|}
\hline $\begin{array}{l}\text { Prescription } \\
\text { category }\end{array}$ & Category definition & Conditions applying to prescription \\
\hline Al & $\begin{array}{l}\text { Antibiotic empirically prescribed in accordance with } \\
\text { principles of antibiotic prescribing for the treatment of infection }\end{array}$ & Conditions I and VI OR Conditions I and VII \\
\hline A2 & $\begin{array}{l}\text { Antibiotic empirically prescribed in accordance with principles } \\
\text { of antibiotic prescribing for the treatment of possible infection }\end{array}$ & Conditions II and VI OR Conditions II and VII \\
\hline B & $\begin{array}{l}\text { Antibiotic empirically prescribed for the treatment of infection } \\
\text { without adherence to the principles of antibiotic prescribing }\end{array}$ & $\begin{array}{l}\text { Conditions I and VIII OR Conditions I and IX OR } \\
\text { Condition I and X OR Conditions I and XI } \\
\text { Conditions II and VIII OR Conditions II and IX. OR Conditions II and X } \\
\text { Condition I OR Condition II OR Condition IV OR Condition VI OR } \\
\text { Condition VII OR Condition VIII OR Condition IX OR Condition X ONLY }\end{array}$ \\
\hline C & Antibiotic prescribed based on culture sensitivity test results & Condition XIII OR Condition XIV \\
\hline $\mathrm{D}$ & $\begin{array}{l}\text { Antibiotic prescribed in accordance with the principles of antibiotic } \\
\text { prescribing for the prevention of infection }\end{array}$ & Conditions III and XV OR Conditions III and XVI \\
\hline $\mathrm{E}$ & $\begin{array}{l}\text { Antibiotic prescribed without adherence to the principles } \\
\text { of antibiotic prescription for the prevention of infection }\end{array}$ & $\begin{array}{l}\text { Conditions III and XVII OR Conditions III and XVIII OR Conditions III and XVIII } \\
\text { Condition III OR Condition XVII OR Condition XVIII ONLY }\end{array}$ \\
\hline $\mathrm{F}$ & $\begin{array}{l}\text { Antibiotic empirically prescribed without adherence to principles } \\
\text { of antibiotic prescribing and in conditions for which antibiotic } \\
\text { prescriptions are not justified }\end{array}$ & Condition IV OR Condition V \\
\hline
\end{tabular}


Table 5. Outpatient prescription rationality categorization.

\begin{tabular}{|c|c|c|}
\hline $\begin{array}{l}\text { Prescription } \\
\text { category }\end{array}$ & Category definition & Conditions applying to prescription \\
\hline $\mathrm{Al}$ & $\begin{array}{l}\text { Antibiotic empirically prescribed in accordance with principles } \\
\text { of antibiotic prescribing for the treatment of infection }\end{array}$ & Conditions I and VI OR Conditions I and VII \\
\hline A2 & $\begin{array}{l}\text { Antibiotic empirically prescribed in accordance with principles } \\
\text { of antibiotic prescribing for the treatment of possible infection }\end{array}$ & Condition II and Condition VI OR Condition II and Condition VII \\
\hline B & $\begin{array}{l}\text { Antibiotic empirically prescribed for the treatment of infection } \\
\text { without adherence to the principles of antibiotic prescribing }\end{array}$ & $\begin{array}{l}\text { Condition I and VIII or Condition I and IX or Condition I and X } \\
\text { Conditions II and VIII OR Conditions II and IX OR Conditions II and XI } \\
\text { Condition I OR Condition II OR Condition IV OR Condition VI OR Condition VII OR } \\
\text { Condition VIII OR Condition IX OR Condition X ONLY }\end{array}$ \\
\hline C & Antibiotic prescribed based on culture sensitivity test results & Condition XII OR XIII \\
\hline D & $\begin{array}{l}\text { Antibiotic empirically prescribed in accordance with the principles } \\
\text { of antibiotic prescribing for the prevention of infection }\end{array}$ & Condition III and XIV OR Condition III and XV \\
\hline $\mathrm{E}$ & $\begin{array}{l}\text { Antibiotic empirically prescribed for the prevention of infection } \\
\text { without adherence principles of antibiotic prescribing }\end{array}$ & Condition II and XVI OR Condition II and XVII \\
\hline $\mathrm{F}$ & $\begin{array}{l}\text { Antibiotics empirically prescribed without adherence to principles } \\
\text { of antibiotic prescribing and in conditions for which antibiotic } \\
\text { prescriptions are not justified }\end{array}$ & Condition IV OR Condition V \\
\hline
\end{tabular}

\section{Study limitations}

The greatest challenge of the use of the method is the ability of a researcher to correctly decide whether or not a prescription being assessed conforms to set criteria against which it is evaluated. Inability to correctly decide on the conformity of a prescription to such set criteria compromises results. To address this challenge in the assessment procedure, informed decisions on the conformity of prescriptions to the assessment criteria were made by using data collection tools that served as reference source on infections and their causative agents as well as the therapeutic and physico-chemical properties of antibiotics.

\section{Conclusions}

A methodology employing an antibiotic prescription assessment instrument based on criteria formulated from principles of antibiotic prescribing has been developed and used successfully in assessing appropriateness of antibiotic prescriptions. It capably classified each prescription into either of two major categories of appropriately and inappropriately prescribed antibiotics and also according to respective purposes and/or reasons for which antibiotics may be prescribed. Considered an advantage of the method, this enabled areas of antibiotic usage with associated problems and the reasons for such problems to be to be identified. In Lesotho and in line with the objectives of this study, employment of the methodology established high rates of inappropriate prescribing of antibiotics in the empiric treatment or prophylaxis of infections in inpatient

Table 6. Frequency of prescription categories in inpatient and outpatient departments.

\begin{tabular}{lcccc} 
Antibiotic prescription categories & \multicolumn{3}{c}{$\begin{array}{c}\text { Frequencies of prescription categories } \\
\text { Inpatient } \\
\text { Prescriptions }\end{array}$} & $\begin{array}{c}\text { Outpatient } \\
\text { prescriptions }\end{array}$ \\
& $n$ & $n \%$ & $n$ & $n \%$ \\
A1 & 55 & 17.9 & 299 & 34.6 \\
A2 & 44 & 14.3 & 378 & 43.8 \\
\hline B & 92 & 30 & 57 & 6.6 \\
C & 4 & 1.3 & 0 & 0 \\
\hline D & 29 & 9.4 & 23 & 2.7 \\
E & 28 & 9.1 & 2 & 0.2 \\
\hline F & 55 & 17.9 & 106 & 12.2 \\
Total & 307 & 100 & 865 & 100 \\
\hline
\end{tabular}

settings. In contrast to results obtained for inpatient settings, high rates of appropriate prescribing of antibiotics according to principles appeared to prevail in outpatient settings. The majority of such prescriptions, however, were identified as prescriptions of antibiotics prescribed for infections with unconfirmed bacterial etiologies.

\section{References}

1. World Health Organization. WHO global strategy for containment of antimicrobial resistance; 2001. http://www.who.int/drugresistance/WHO_Global_Strategy_Englis h.pdf Accessed: 1 April 2010.

2. Loeb M, Simor AE, Landry L, et al. Antibiotic use in Ontario facilities provides chronic care. J Gen Intern Med 2001;16:376-83.

3. Gonzales R, Bartlett JG, Besser RE, et al. Principles of appropriate antibiotic use for treatment of non-specific upper respiratory tract infections in adults: background. Ann Intern Med 2001;134:490-4.

4. Holmes KK. Sexually transmitted diseases: overview and clinical approach. In: Kasper DL, Brunwald E, Fausi AS, et al., eds. Harrison's principles of internal medicine. New York: McGraw-Hill; 2005. pp 762-75.

5. Aronson JK. Editors' view: rational prescribing, appropriate prescribing. Br J Clin Pharmacol 2004;57:229-30.

6. Chambers HF. Antimicrobial agents. In: Hardman JG, Limbird LE, eds. The pharmacological basis of therapeutics. New York: McGraw-Hill; 2001. pp 1143-1266.

7. Guglielmo BJ. Principles of infectious diseases. In: Koda-Kimble MA, Young LY, Alldredge BK, et al., eds. Applied therapeutics: the clinical use of drugs. Philadelphia, PA: Wolters Kluwer Health/Lippincott \& Wilkins; 2008. pp 56.1 - 56.25.

8. Adorka M, Mitonga KH, Allen K, et al. The impact of appropriate antibiotic prescribing on treatment evaluation parameters. $\mathrm{J}$ 
Public Health Africa 2013;4:e2.

9. Erbay A, Bodur H, Akinci E, et al. Evaluation of antibiotic use in intensive care units of a tertiary care hospital in Turkey. J Hosp Infect 2009;59:53-61.

10. Trap B, Hansen EH. Cotrimoxazole prescribing by dispensing and non- dispensing doctors: do they differ in rationality?. Trop Med Int Health 2002;7:878-85.

11. Thuong M, Shortgen F, Zazempa V, et al. Appropriate use of restricted antimicrobial agents in hospitals: the importance of empirical therapy and assisted re-evaluation. J Antimicrob Chemother 2000;46: 501-8.

12. Alves DA, Cunha AJL, Amaral J, et al. Inappropriate antibiotic prescription to children with acute respiratory infection in Brazil. Indian Pediatr 2003;40:7-12.

13. Akkerman AE, Kuyenhoven MM, Van der Wouden JC, et al. Analysis of under-and over prescribing of antibiotics in acute otitis media in general practice. J Antimicrob
Chemother 2005;56:569-74.

14. Martinez M, Inglada L, Ochoa C, et al. Assessment of antibiotic prescription in acute urinary tract infection in adults. $\mathrm{J}$ Infect 2007;4:235-244.

15. Maciulaitis R, Janusonis T, Petrikaite V, et al. Assessment of antibiotic use and comparison with recommendation for their rational use. Medicina (Kaunas) 2006;42: 999-1005.

16. Finch R. Antimicrobial therapy: principles of use. Medicine 2005;33:42-6.

17. Thompson RL, Wright AJ. General principles of antimicrobial therapy. Mayo Clin Proc 1998;73:995-1006.

18. Daouiche R0. Device associated infections: a macroproblem that starts with microadherence. Clin Infect Dis 2001;33: 1567-72.

19. Grimwade K, Sturm AW, Nunn AJ, et al. Effectiveness of co-trimoxazole prophylaxis on mortality in adults with tuberculosis in rural South Africa. AIDS 2005;19:163-8.
20. Sabella C, Golfarb J. Principles of selection and use of antimicrobial agents. Semin Pediatr Infect Dis 1999;10:3-13.

21. Archer GL, Polk RE. Treatment and prophylaxis of bacterial infections. In: Kasper, DL, Brunwald E, Fausi AS, et al., eds. Harrison's principles of internal medicine. New York: McGraw-Hill; 2005. pp 789-806.

22. Barlett JG, Dowell SF, Mandel LA, et al. Practice guidelines for the management of community acquired pneumonia in adults: Infectious Disease Society of America. Clin Infect Dis 2000;31:347-82.

23. Gaur AH, English BK. The judicious use of antibiotics - an investment towards optimised health care. Indian J Paediatr 2006; 73:343-50.

24. Hart AM. An evidenced based approach to the diagnosis and management of acute respiratory infections. J Nurs Practitioners 2007;3:607-61. 